\title{
A Fuzzy Approach for the Treatment of the Human Diseases Resulting from Exposure to Electromagnetic Fields
}

\author{
Ioan FELEA ${ }^{1}$, Marius LOLEA ${ }^{1}$, Simona DZITAC ${ }^{1,2^{*}}$ \\ ${ }^{1}$ University Of Oradea, 1 Universitatii, Oradea, 410087, Romania \\ ioanfelea@gmail.com,mlolea@yahoo.com \\ ${ }^{2}$ Cercetare Dezvoltare Agora, 8 Piata Tineretului, Oradea, 410526, Romania \\ simona@dzitac.ro (*Corresponding author)
}

\begin{abstract}
Among the current risks of (non-specific) occupational diseases or risks of persons, one may also include the risk of exposure to electric, magnetic and electromagnetic fields (EMF). This problem has been in the hands of specialists for about six decades, but the questions regarding EMF effects and the admissible limits of the EMF's characteristic sizes have still not been answered. This paper aims to increase the accuracy of the EMF effects assessment on people exposed to stabilized regime areas of power plants. Firstly, the problem proposed to be solved is presented. Secondly, the fuzzy approach to the treatment we propose for assessing the severity caused by the human exposure to the stationary EMF is put forward together with all the particularities and modalities of fuzzy treatment in this case. The paper contains applications based on experimental data related to the assessment of the consequences of EMF exposure from one power substation. The final part of the paper presents the conclusions of the treatment and the developed applications.
\end{abstract}

Keywords: Electromagnetic field, Effects, Fuzzy modelling, Stabilized regime.

\section{Introduction}

The basic issue of electromagnetic radiation (EMR) generated by electromagnetic field installations and the effects on the natural and artificial environment is the subject of many scientific, technological and regulatory concerns. In the present paper we will refer to EMF on industrial frequency generated by power plants (power lines, power substations etc.) will be approached, with certain effects in its presence area, of which evaluation and counselling are subject to intense concerns without definite results from the international scientific community. In (Billel, Abdesselam and Zhang, 2001), the experimental results obtained as a consequence of the electromagnetic radiation (EMR) level investigation in an interconnection power station (PS) $-220 / 90 / 60 / 30 \mathrm{kV}$ - is presented. Further, the methodology for measuring the two EMF characteristic vectors (E - electric field strength, $\mathrm{B}-$ magnetic flux density) is presented. The obtained results are compared to the limits established by the standards, without referring to the concrete ways of evaluating the effects. The EMF modelling of high power equipment - the arc furnace, is the subject of the paper (Pănoiu et al., 2009), without reference to the effects of EMF's presence. The application of artificial neural networks to solve the interference problems of EMF generated by the high voltage power lines (HVPL) is the subject of the paper (Dan, 2012). To evaluate the effect of EMF on underground metallic pipes, the authors propose to use the magnetic vector potential (MVP) comprising only the EMF magnetic component and not referring to the effects on living organisms.

The main physical phenomena that characterize the exposure in electric field are (Cleveland, 2005, Caputa et al., 2002 and Felea et al., 2010): direct perception, the accumulation of electric charge by induction as this phenomenon is emphasized by increasing the speed variation of EMF characteristic vectors with load variation in transient regimes. Parameters characterizing the biological effects of the exposure of the human body in electric field are: electric field strength (E) and induced current density (J). The presence of the human body affects the spatial distribution of an electric field.

The analysis of effects is conducted by evaluating the two parameters (E, J), and applying the laws of Electrical Engineering (Hănţilă et al., 1997), given the quantities of material values (conductivity and permittivity). In assessing the effects of electric field on the human body both values and the current distribution play an important role. These size ratings are used to assess simulation methods and experimental approaches based model. Characteristic sizes (CS) for the biological effects of magnetic field are magnetic flux density (B) and induced current density (J). The link between the two parameters is based on the law of electromagnetic induction and electric conduction law, having the influence factor as equivalent for the conductivity of the human body (Caputa et al., 
2002 and Felea et al., 2010). Currently, it operates primarily with the accepted limits of certain sizes, repectively: $\mathrm{Ea}$ - the admissible value of electric field strength, $\mathrm{Ba}$ - the admissible value of magnetic flux density, SARa - the admissible value of "specific energy absorption rate", easily measurable limits based on thermal effect of EMF on the human body. A key parameter used in setting the allowable limits is "specific energy absorption rate" of power absorption (Polk, 1991, CE, 1987 and CENELEC, 1993):

$\mathrm{SAR}=\mathrm{dS}=\frac{\mathrm{d}}{\mathrm{dt}}\left(\frac{\mathrm{dW}}{\gamma \cdot \mathrm{dV}}\right)=\frac{\sigma \cdot \mathrm{E}_{\mathrm{i}}^{2}}{\gamma}$

With:

$\mathrm{dW}$ - the amount of energy dissipated / absorbed;

$\mathrm{dV}$ - volume element;

$\gamma$ - biological tissue density;

Ei - electric field strength in tissue.

There are several organizations, internationally recognized (CE, 1987, CENELEC, 1993 and ICNIRP, 2009), which set acceptable limits for size (E, B) starting from the fact that the SAR indicator cannot be measured directly for professional and public area. International Commission on Nonionizing Radiation Protection (ICNIRP) is a nongovernmental organization whose acts, based on a broad consensus on the scientific results of the protection against the effects of EMF are recommended by the EC (European Commission) and are the basis of national standards.

Fuzzy theory and its potential use for describing and evaluating processes in technical systems was developed and first presented to the international scientific community by Prof. Lotfi Zadeh (Zadeh, 1988). Currently, fuzzy theory has multiple applications including those dealing with EMFrelated problems.

In (Damousis et al., 2001, Damousis et al., 2002), a fuzzy model adapted to determine the induction of the magnetic field is used in the conditions of random accidental Power lines (PL) events, and a genetic algorithm for fuzzy model parameters is being developed. In (Boumaiza et al., 2015) the use of the fuzzy logic is proposed to predict the effects of EMF on human health, starting from the reality of uncertain and imprecise effects caused by parameters such as frequency, B, time of exposure, distance, age and gender. The paper presents a principle approach for high frequency
EMF, considering only one of the characteristic sizes (B), and without proposing a way to evaluate the effects. To estimate EMF's CS around HVPL, (Radulović and Ranković, 2007) propose the use of adaptive systems based on fuzzy interference networks (ANFIS). The treatment is individual (electric field strength, magnetic flux density), only for the two CS, without addressing the EMF effects. The subject is resumed in (Lakshmi and Sivakami, 2012) where the authors propose the use of ANFIS to solve the mathematical model of EMF distribution generated by HVPL in normal and short-circuit conditions. The authors use the finite element method to solve the equations describing the electromagnetic wave using the Matlab software. The application refers to $500 \mathrm{kV}$ single and double circuit electrical lines for which the magnetic induction distribution is evaluated without reference to the other CS (E) and to the EMF effects.

Starting from the general methodology for assessing the risk of occupational disease, section two of the paper presents the author's proposal regarding the methodology for evaluating the consequence of human exposure to stabilized EMF. Given the nature of characteristic vectors (E, B) the necessity and utility of fuzzy treatments are justified, specifying the particularities by applying this modeling in this case. Section three contains specifications and results by the fuzzy treatment of the consequence severity of human exposure to EMF in the PS. Conclusions of the obtained results and the perspective on their application are summarized in section four of the paper.

\section{Formulation of the Problem and Working Methodology}

According to (Cleveland, 2005 and Nitu et al., 1981), the risk has a two-dimensional (vectorial) size:

$\mathrm{r}=\mathrm{f}\left(\mathrm{p}_{\mathrm{UE}}, \mathrm{C}\right)$

Where, $\mathrm{p}_{\mathrm{UE}}$ is the probability of the unwanted event occurring (UEO), $\mathrm{C}$ - severity of UEO consequence.

No one can escape today the omnipresence of artificial EMF. In this case, UEO is: "the presence of the person (human) in the EMF dangerously (EMFd)" (Felea et al., 2008). By EMFd one refers to the EMF whose $(\mathrm{B}, \mathrm{E})$ exceed the admissible values $(\mathrm{Ba}, \mathrm{Ea})$. 
The unitary gravity of the consequence (c) is manifested by the degree of damage to the health of a person exposed to EMFd. In the international and European standard, SAR is used to assess the level of this magnitude, the "specific energy absorption rate" (CE, 1987 and CENELEC, 1993). According to the actual phenomena and conditions of the EMF generating installations (GI - EMF) - electrical substations, power lines, traction equipments - the assessment of the consequence can be done in the stabilized regime (the usual regime) and in the transient regime (overload in voltage and / or current). This paper aims at the stabilized regime of low - frequency of GI - EMF.

The cumulative (total) consequences of the exposure of a certain number of $\mathrm{M}$ persons in a time analysis (TA) range to an EMF, can be expressed as follows (Felea, Lolea and Secui, 2017):

$$
\mathrm{C}=\sum_{\mathrm{j}=1}^{\mathrm{M}} \mathrm{p}_{\mathrm{UE}} \cdot \mathrm{c}_{\mathrm{j}}
$$

Note that cumulative consequences also apply to every person exposed to multiple sources. If a mean (non-personalized) value of the consequence is taken into consideration, as it follows from the current norms (ICNIRP, 2009, HG 1136, 2006 and O.M.S., 2006), then it can be written:

$$
\mathrm{C}=\mathrm{C}_{\text {med }} \sum_{\mathrm{j}=1}^{\mathrm{M}} \mathrm{p}_{\mathrm{UE}_{\mathrm{j}}}
$$

In this way, (c) becomes deterministic; the analysis being focused on the $\mathrm{p}_{\mathrm{UE}}$ variable, whose method of evaluation is the subject of other papers (ICNIRP, 2009, Felea et al., 2017 and Felea et al., 2008).

Fuzzy theory and modelling refers to random (possible) inaccurate / vague events (Zadeh, 1988). It is also the case of the events (UEO) that are considered in this paper. Given the distribution of the measured values (Bm, Em) the Gaussian and triangle functions will be used (Zadeh, 1988, Dziţac, 2009, and Groumpos, 2018).

Two essential aspects of fuzzy treatment are:

- Determining the number of steps (levels) of the variable;

- Establishing the connection between the levels and the value range of the respective variable, the numerical significance of the fuzzy levels.

- The literature (scientific and normative) refers to the three levels of the risk of human exposure to EMF (B, E, SAR), thus (CENELEC, 1993 and ICNIRP, 2009):

- The International Commission on NonIonizing Radiation Protection (ICNIRP) recommends for the environment, $\mathrm{SAR}_{\mathrm{a}}=$ $0,08 \mathrm{~W} / \mathrm{kg}$;

- The European Commission (EC) has established admissible head and body values $\mathrm{SAR}_{\mathrm{a}}=2 \mathrm{~W} / \mathrm{kg}$ by Directive 2004/40 / EC.

American standards (ICNIRP, 2009) set a value lower than the one established by EC, respectively $\mathrm{SAR}_{\mathrm{a}}($ head, body $)=1.6 \mathrm{~W} / \mathrm{kg}$.

For mobile telephony in (O.M.S., 2006), the reference is made to the following irradiation (IR) steps:

Low IR: SAR <0,2 W / kg;

Reduced IR: SAR $\in[0,2 \div 0,5] \mathrm{W} / \mathrm{kg}$;

Average IR: SAR $\in[0,5 \div 1] \mathrm{W} / \mathrm{kg}$;

High IR: SAR $\geq 1 \mathrm{~W} / \mathrm{kg}$.

In IEC 61000-4-1 (CEI, 2006), severity levels are determined by involving the performance of electromagnetic immunity tests for equipment's / devices, as follows:

Table 1. Levels of severity for specific EMF sizes, $\mathrm{E}$ and $\mathrm{H}$ by (CEI, 2006)

\begin{tabular}{|c|c|c|}
\hline \multirow{2}{*}{ Levels } & \multicolumn{2}{|c|}{ Values } \\
\cline { 2 - 3 } & $\mathbf{E}[\mathbf{V} / \mathbf{m}]$ & $\mathbf{H}[\mathbf{A} / \mathbf{m}]$ \\
\hline 1 & 1 & 1 \\
\hline 2 & 3 & 3 \\
\hline 3 & 10 & 10 \\
\hline 4 & 30 & 30 \\
\hline 5 & - & 100 \\
\hline
\end{tabular}

According to the ICNIRP recommendations (CE, 1987 and CENELEC, 1993), for the frequencies in the range [ 25 to 300$] \mathrm{Hz}$, the admissible values for occupational exposure to EMF, are:

$E_{a}=500 / f[k V / m] ;$ for. $\mathrm{f}=50 \mathrm{~Hz} \rightarrow$

$\mathrm{E}_{\mathrm{a}}^{\mathrm{a}}=10000 \mathrm{~V} / \mathrm{m}, \mathrm{B}_{\mathrm{a}}=10^{-3} \mathrm{~T}=1 \mathrm{mT}$

Admissible values for public places (ambient limit) at $50 \mathrm{~Hz}: \mathrm{E}_{\mathrm{a}}=5 \mathrm{kV} / \mathrm{m}$;

$\mathrm{B}_{\mathrm{a}}=2 \cdot 10^{-4} \mathrm{~T}=0,2 \mathrm{mT}$

In $[21]$, for $\mathrm{f}=[0.025-0.8 \mathrm{kHz}]$ is recommended for the public exposure:

$\mathrm{E}_{\mathrm{a}}=250 / \mathrm{f}=250 / 50=5 \mathrm{kV} / \mathrm{m}$

$\mathrm{B}_{\mathrm{a}}=5 / \mathrm{f}=5 / 50=0,1 \mu \mathrm{T}, \mathrm{H}_{\mathrm{a}}=4 / \mathrm{f}[\mathrm{A} / \mathrm{m}]$ 
Taking into consideration the above mentioned information, the fuzzy evaluation consequence to the EMF is considered, starting from the four levels of the two characteristic sizes (E, B), as seen in Table 2 of the human exposure.

Table 2. Levels of CS $[X \equiv\{E, B\}]$

\begin{tabular}{|c|c|c|c|}
\hline Code & Level & Signification & $\begin{array}{c}\text { The values } \\
\text { range } \\
\text { relative to } \\
\mathbf{X}_{\mathbf{a}}\left(\mathbf{E}_{\mathbf{a}}, \mathbf{B}_{\mathbf{a}}\right)\end{array}$ \\
\hline 1 & Negligible & Insignificant & $\mathrm{X} \leq 1 / 2 \mathrm{X}_{\mathrm{a}}$ \\
\hline 2 & Small & Significant & $\begin{array}{c}1 / 2 \mathrm{X}_{\mathrm{a}}<\mathrm{X} \\
\leq \mathrm{X}_{\mathrm{a}}\end{array}$ \\
\hline 3 & Big & $\begin{array}{c}\text { High } \\
\text { signification }\end{array}$ & $\begin{array}{c}\mathrm{X}_{\mathrm{a}}<\mathrm{X} \leq \\
2 \mathrm{X}_{\mathrm{a}}\end{array}$ \\
\hline 4 & Very big & $\begin{array}{c}\text { Very high } \\
\text { signification }\end{array}$ & $\mathrm{X}>2 \mathrm{X}_{\mathrm{a}}$ \\
\hline
\end{tabular}

Consequence level (C) as well as SAR level are proportional to the multiplication of CS (E x B). 5 levels will be selected to characterize the consequences and, by default, the risk of human exposure to EMF with the following significance - presented in Table 3.

Table 3. Fuzzy characterization of the consequence of exposure to EMF

\begin{tabular}{|c|c|c|}
\hline Code & Signification & Levels (E,B) \\
\hline 1 & $\begin{array}{c}\text { Very small } \\
\text { (insignificant) }\end{array}$ & $(1,1)$ \\
\hline 2 & Small & $\begin{array}{c}(1,2) ;(2,1) ;(1,3) ; \\
(3,1)\end{array}$ \\
\hline 3 & Medium & $\begin{array}{c}(2,2) ;(1,4) ;(4,1) ; \\
(2,3) ;(3,2)\end{array}$ \\
\hline 4 & High & $(2,4) ;(4,2) ;(3,3)$ \\
\hline 5 & Very High & $(3,4) ;(4,3) ;(4,4)$ \\
\hline
\end{tabular}

The flow of information processing according to fuzzy modeling is the following (Zadeh, 1988, Damousis et al., 2002 and Dziţac, 2009):

\section{INPUT DATA $\Rightarrow$ FUZZIFICATION $\Rightarrow$ INFERENCE- DEFUZZIFICATION $\Rightarrow$ OUTPUT DATA}

In the present paper for the practical application of fuzzy evaluation of the severity consequence of the exposure in the low frequency stabilized EMF, the fuzzy module from the MATLAB software is used, which has predefined functions for the different phases of fuzzy calculation (fuzzy, inferential, defuzzification). These functions are linked to two external modules (made in $\mathrm{C}++$ ), namely: "inference system" and "fuzzy engine". With the predefined functions, SIMULINK can also be launched to simulate. The typical structure of fuzzy inference systems is a model that performs a certain connection: firm input value - input membership functions - inference rules - output characteristics - output membership functions - firm output value (Radulović and Ranković, 2007, Lakshmi and Sivakami, 2012).

In the Matlab software, tools of the module dedicated to fuzzy logic systems (Fuzzy Toolbox) are presented in the block diagram of Figure 1 (Matlab).

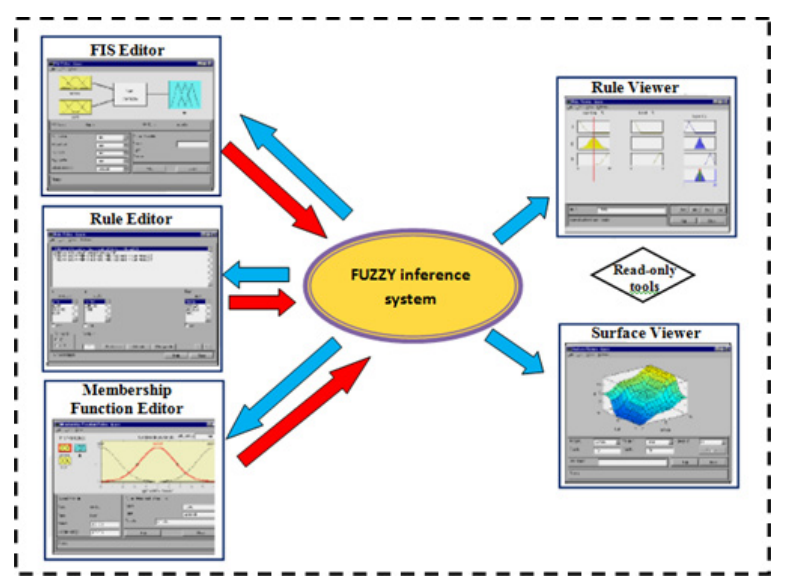

Figure 1. Graphic tools for fuzzy modeling and the interconnection of their dedicated components in Matlab software

Input variables are the two CSs $(\mathrm{E}, \mathrm{B})$ whose values come from the measurements performed by the authors. In order to solve the applications, the program settings for the analysis parameters are as follows:

- $\quad$ The type of fuzzy method: mamdani;

- Number of input variables: 2;

- Type of input variables: electric field strength, magnetic flux density;

- Inference rules: 16;

- Number of effect levels: 5;

- Type of damage levels: insignificant, small, medium, high, very high;

- Composition operator: "AND”; 
- Defuzzification based on: maximum sampling method;

- Fuzzy number assigned to the membership function: triangular of real variables.

The sequence of steps to be taken for each GIEMF is presented in Figures $2 \div 7$.

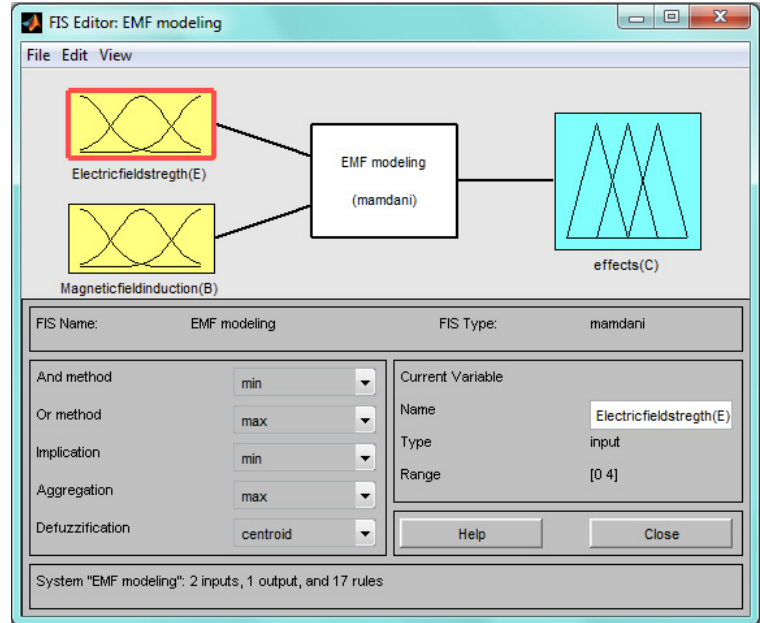

Figure 2. Creating inputs

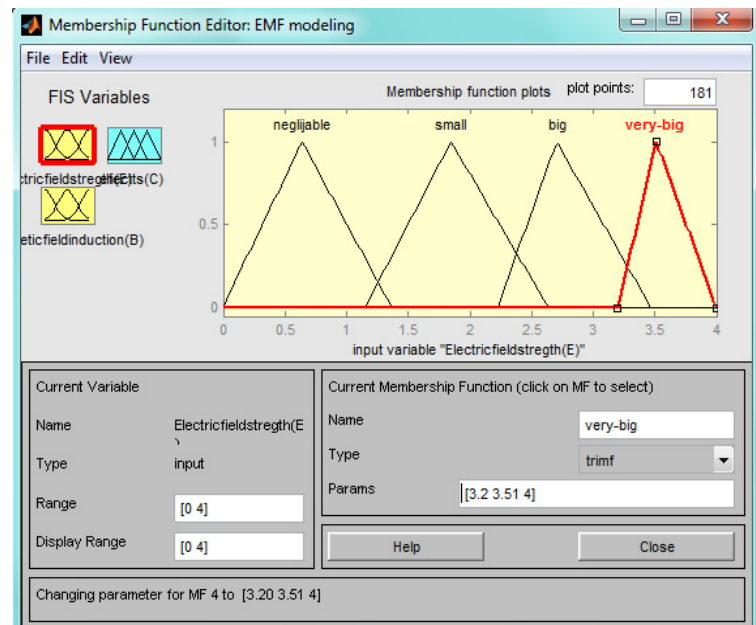

Figure 3. Assigning levels of input sizes

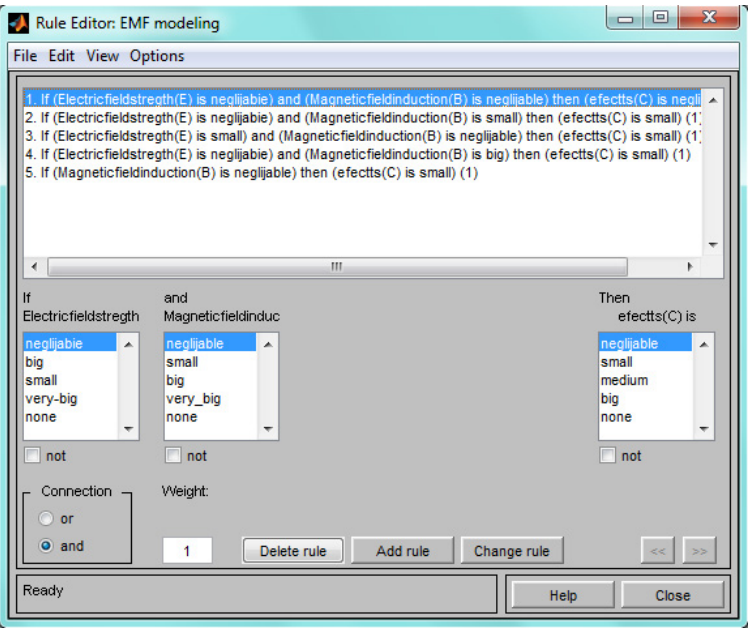

Figure 4. Creating the set of inference rules

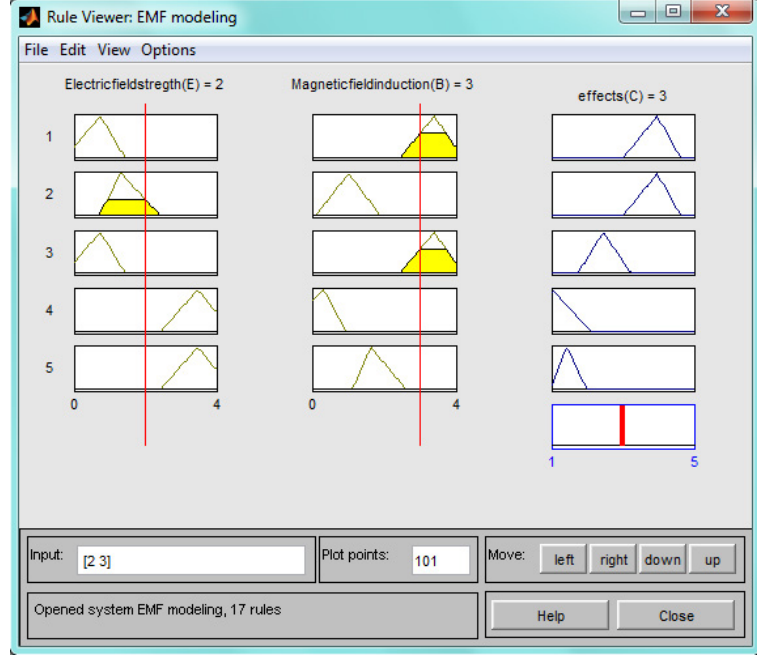

Figure 5. View cumulative effects

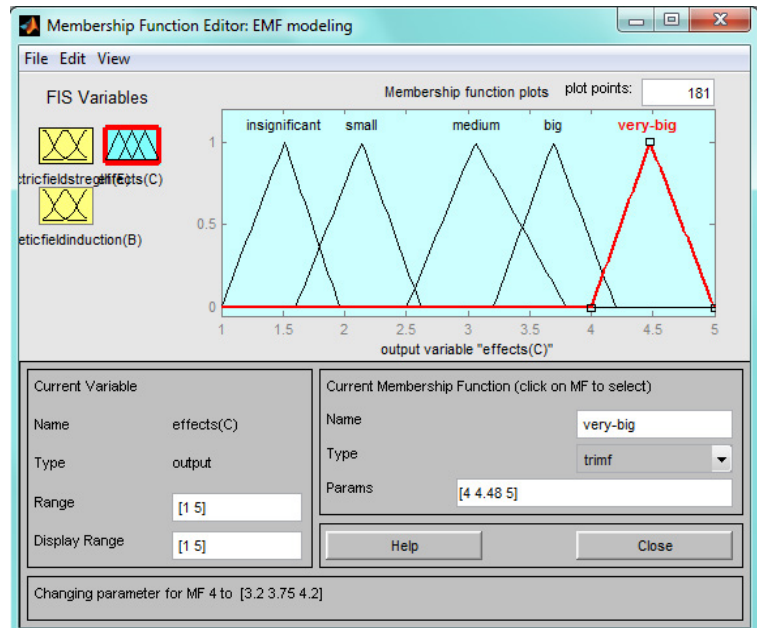

Figure 6. Generating Outputs (Effects)

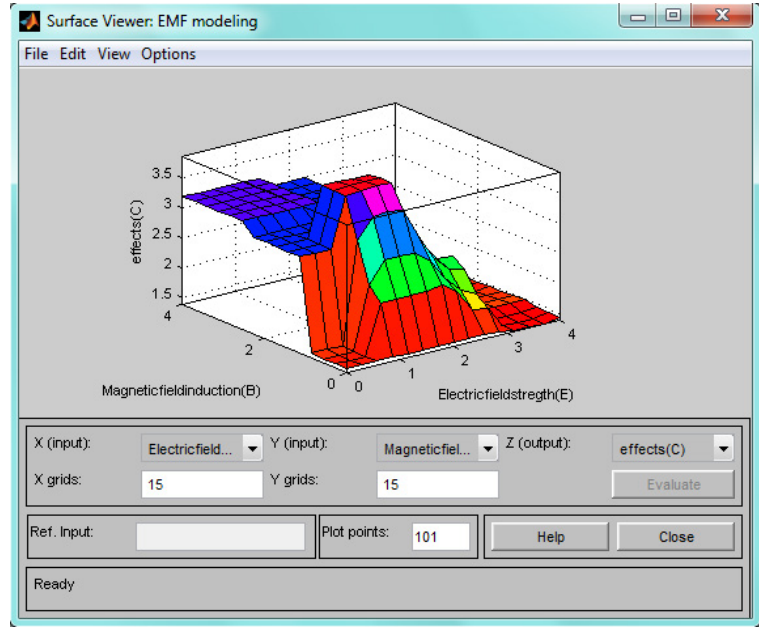

Figure 7. Generating process of the decision surface

\section{Application}

The evaluation methodology presented was applied with reference to Power Substations (PS) 
Table 4. Electrical field strength statistics for PSSI - HV

\begin{tabular}{|c|c|c|c|c|}
\hline Code & Level & Signification & Value ranges & No. of presences \\
\hline 1 & Negligible & Insignificant & $\mathrm{E} \leq 1 / 2 \mathrm{E}_{\mathrm{a}}$ & 137 \\
\hline 2 & Small & Significant & $1 / 2 \mathrm{E}_{\mathrm{a}}<\mathrm{E} \leq \mathrm{E}_{\mathrm{a}}$ & 47 \\
\hline 3 & Big & High signification & $\mathrm{E}_{\mathrm{a}}<\mathrm{E} \leq 2 \mathrm{E}_{\mathrm{a}}$ & 12 \\
\hline 4 & Very Big & Very High signification & $\mathrm{E}>2 \mathrm{E}_{\mathrm{a}}$ & 4 \\
\hline
\end{tabular}

$\mathrm{E}_{\mathrm{a}}=10000 \mathrm{~V} / \mathrm{m}$ in conformity with (HG 1136, 2006)

Table 5. Magnetic flux density statistics for PSSI - HV

\begin{tabular}{|c|c|c|c|c|}
\hline Code & Level & Signification & Value ranges & No. of presences \\
\hline 1 & Negligible & Insignificant & $\mathrm{B} \leq 1 / 2 \mathrm{~B}_{\mathrm{a}}$ & 158 \\
\hline 2 & Small & Significant & $1 / 2 \mathrm{~B}_{\mathrm{a}}<\mathrm{B} \leq \mathrm{B}_{\mathrm{a}}$ & 32 \\
\hline 3 & Big & High signification & $\mathrm{B}_{\mathrm{a}}<\mathrm{B} \leq 2 \mathrm{~B}_{\mathrm{a}}$ & 8 \\
\hline 4 & Very Big & Very High signification & $\mathrm{B}>2 \mathrm{~B}_{\mathrm{a}}$ & 2 \\
\hline
\end{tabular}

Table 6. Statistics of doubles that characterize the severity of the consequence for PSSI - HV

\begin{tabular}{|c|c|c|c|}
\hline Code & Signification & Levels of (E,B) & Appearances number \\
\hline 1 & Very Small & $(1,1)$ & 295 \\
\hline 2 & Small & $(1,2) ;(2,1) ;(1,3) ;(3,1)$ & 689 \\
\hline 3 & Medium & $(2,2) ;(1,4) ;(4,1) ;(2,3) ;(3,2)$ & 479 \\
\hline 4 & High & $(2,4) ;(4,2) ;(3,3)$ & 105 \\
\hline 5 & Very High & $\mathrm{N}(3,4) ;(4,3) ;(4,4)$ & 32 \\
\hline
\end{tabular}

Table 7. Electrical field strength statistics for PSSI - MV

\begin{tabular}{|c|c|c|c|c|}
\hline Code & Level & Signification & Value ranges & No. of presences \\
\hline 1 & Negligible & Insignificant & $\mathrm{E} \leq 1 / 2 \mathrm{E}_{\mathrm{a}}$ & 163 \\
\hline 2 & Small & Significant & $1 / 2 \mathrm{E}_{\mathrm{a}}<\mathrm{E} \leq \mathrm{E}_{\mathrm{a}}$ & 35 \\
\hline 3 & Big & High signification & $\mathrm{E}_{\mathrm{a}}<\mathrm{E} \leq 2 \mathrm{E}_{\mathrm{a}}$ & 2 \\
\hline 4 & Very Big & Very High signification & $\mathrm{E}>2 \mathrm{E}_{\mathrm{a}}$ & 0 \\
\hline
\end{tabular}

$\mathrm{B}_{\mathrm{a}}=500 \mu \mathrm{T}$ in conformity with (HG 1136, 2006)

Table 8. Magnetic flux density statistics for PSSI - MV

\begin{tabular}{|c|c|c|c|c|}
\hline Code & Level & Signification & Value ranges & No. of presences \\
\hline 1 & Negligible & Insignificant & $\mathrm{B} \leq 1 / 2 \mathrm{~B}_{\mathrm{a}}$ & 150 \\
\hline 2 & Small & Significant & $1 / 2 \mathrm{~B}_{\mathrm{a}}<\mathrm{B} \leq \mathrm{B}_{\mathrm{a}}$ & 31 \\
\hline 3 & Big & High signification & $\mathrm{B}_{\mathrm{a}}<\mathrm{B} \leq 2 \mathrm{~B}_{\mathrm{a}}$ & 15 \\
\hline 4 & Very Big & Very High signification & $\mathrm{B}>2 \mathrm{~B}_{\mathrm{a}}$ & 4 \\
\hline
\end{tabular}

Table 9. Statistics of doubles that characterize the severity of the consequence for PSSI - MV

\begin{tabular}{|c|c|c|c|}
\hline Code & Signification & Levels of (E,B) & Appearances number \\
\hline 1 & Very Small & $(1,1)$ & 313 \\
\hline 2 & Small & $(1,2) ;(2,1) ;(1,3) ;(3,1)$ & 709 \\
\hline 3 & Medium & $(2,2) ;(1,4) ;(4,1) ;(2,3) ;(3,2)$ & 466 \\
\hline 4 & High & $(2,4) ;(4,2) ;(3,3)$ & 87 \\
\hline 5 & Very High & $\mathrm{N}(3,4) ;(4,3) ;(4,4)$ & 25 \\
\hline
\end{tabular}


from the Bihor Power System (BPWS). Evidence and processing of the results was carried out with the established methodology (Felea et al., 2010 and Felea, Lolea, Secui, 2017). For example, the results for PS - Sinteza Iosia (PSSI) are presented.

The statistics of the grouped values measured by levels are presented separately for the HV (PSSI - HV) side in Tables $4 \div 6$, and for MV side of PS (PSSI-MV) in Tables $7 \div 9$, respectively.

The total number of measured values is 200 for each CS type and voltage level. For the total number of inference rules set out and presented in Table 3, the set of rules conceived, based on the condition "IF", "AND", "THEN" is shown in Figure 8.

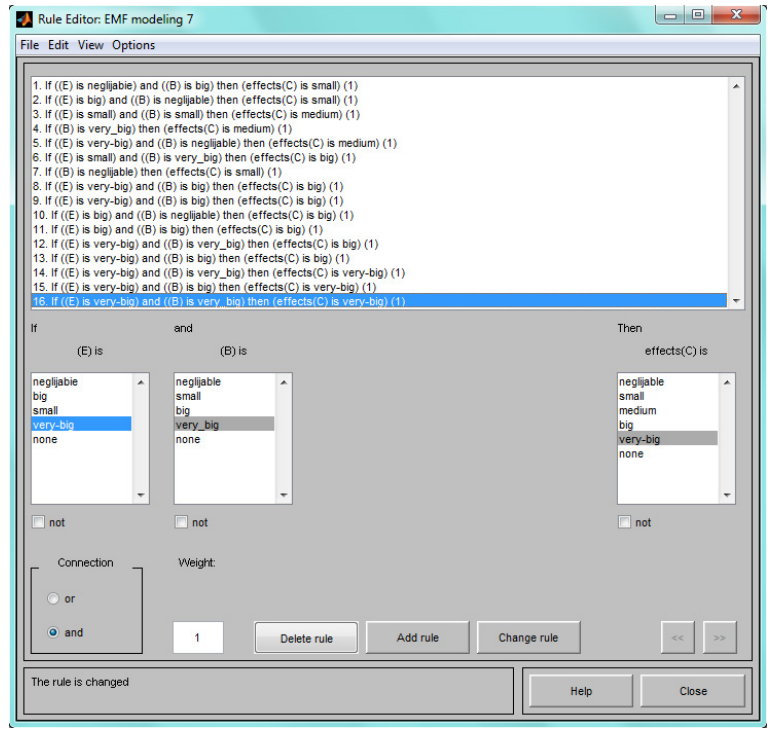

Figure 8. Input of established rules in the MATLAB toolbox for PSSI

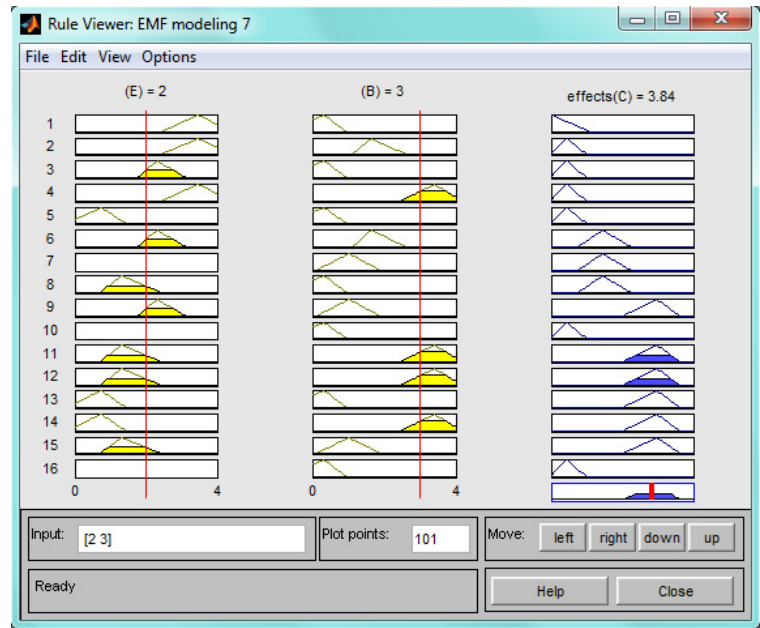

Figure 9. Chart of rules and effects for PSSI
The graphical representation of the inference rules and the generation of effects of the exposure by characteristic vectors $(\mathrm{E}, \mathrm{B})$ contribution are shown in Figure 9. The decision surfaces on the effect of EMF exposure present in PSSI are shown in Figures $10 \div 11$

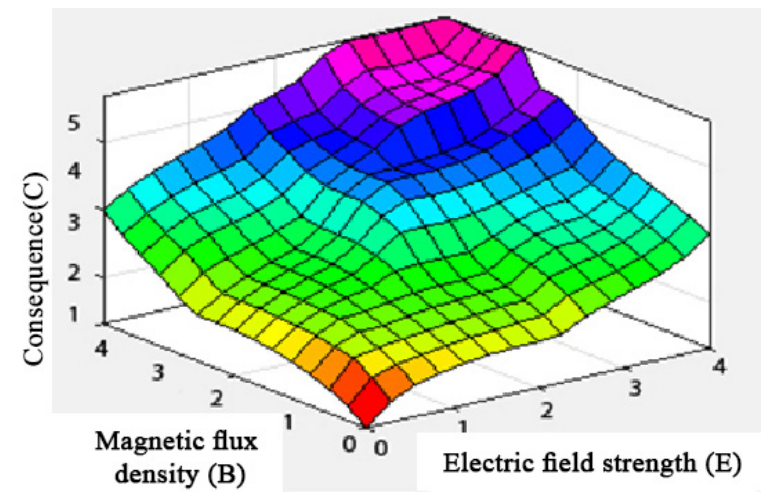

Figure 10. Level of severity of the consequences of EMF exposure in PS Ioşia Oradea at HV level shown through decision surface

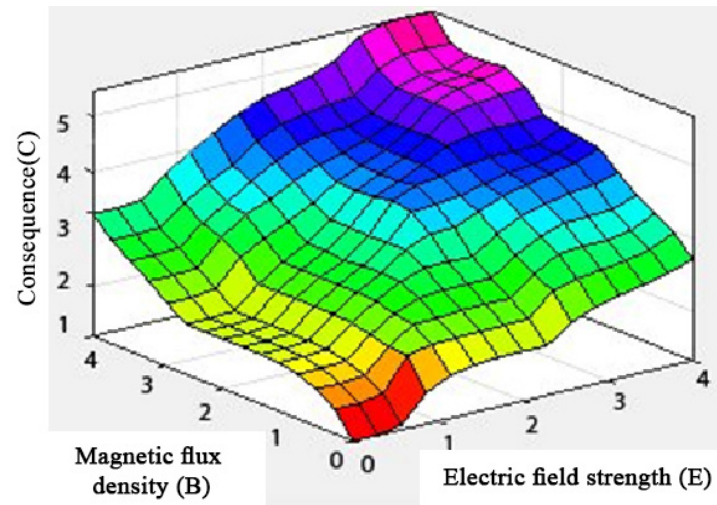

Figure 11. Level of severity of the consequences of EMF exposure in PS Ioşia Oradea at MV shown through decision surface

\section{Conclusion}

The omnipresence of artificial EMF implies that there is a potential risk of affecting exposed persons, both in the professional and civil environments.

The identification of EMF generated by power plants is an issue of high relevance and importance for the proper protection of people who can enter their area of existence. For this purpose, it is essential to assess as accurately as possible the severity of the consequences of exposure of persons to the EMF. Whereas characteristic 
values of EMF (E, B) and by default "specific energy absorption rate" (SAR) have imprecise values structured on levels, for proper accuracy assessment of exposure risk to EMF, the application of fuzzy modelling is recommended. In this paper the methodology of a fuzzy approach to the treatment of the diseases associated with the human exposure to the stabilized EMF is presented. Its proposed structure has five levels (from insignificant to very high) in correlation with the specific energy absorption rate (SAR) levels. The levels obtained by combining the four levels on which CS is structured reflects the possibility of structuring/classifying the severity of the consequences of the human exposure to EMF into 5 levels. For the effective application of the fuzzy evaluation of the severity consequences of exposure of individuals in the EMF, it is recommended to use the fuzzy Toolbox from the Matlab software, by employing the "mamdani" fuzzy particular method, the triangle membership function and the medium - defuzzification method. The methodology was applied to all 14 PS. in the Bihor PWS, for which the authors carried out measurements on the EMF (E and B) characteristic values and presented only one of them - PS Sinteza-Iosia (PSSI). The structuring of the results was made on the two voltage levels (HV and MV) of the energy transformation chain, in the PS. For both voltage levels, one can notice

\section{REFERENCES}

1. Billel, A. R., Abdesselam, B. \& Zhang, X. (2001). Electromagnetic radiation inside high voltage substation, Revue Roumaine des Sciences Techniques - Serie Électrotechnique et Énergétique - RRST, 61(2), 178-182.

2. Boumaiza, S., Bouharati, S., Bouzidi, A. \& Lalaoui, M. (2015). Predicting Health Effects of Electromagnetic Radiation in Algeria Using Fuzzy Logic, International Journal of Public Health Research, 3(6), 352-356.

3. Caputa, K., Dimbylow, P. J., Dawson, T. W. \& Stuchly, M. A. (2002). Modelling fields induced in humans by $50 / 60 \mathrm{~Hz}$ magnetic fields: reliability of the results and effects of model variations, Physics in Medicine and Biology, 47(8), 1391-1398. a balanced influence of the two characteristic sizes (E, B) on the probable effect (gravity of the consequence), by registering the values of the characteristic sizes at all levels of influence (exception, level 4 - medium voltage). In all 4 cases the values of the negligible level 1 - of the CS are predominant. By combining the levels of the two characteristic sizes according to the reality (the measurements have been done simultaneously the same point for $\mathrm{E}$ and $\mathrm{B}$ ) relatively high risk levels (probable consequence) are obtained. The predominant levels are level 2 (small) and 3 (average), with a slightly higher probability on the MV (medium voltage) side. The obtained results reflect the utility of fuzzy treatment for assessing the severity of the consequences of exposure of individuals to EMF and its applicability with reference to the other power substations. It has been considered useful to extend this approach, and further on the refer to the transitional regime of GI-EMF so that the decision-makers in the field may be adequately advised on the results obtained from this research.

\section{Acknowledgements}

This research is partially supported by "Cercetare Dezvoltare Agora" (R and D Agora) of Agora University from Oradea, Romania.

4. CEI - 61000 - 4-1 (2006). Electromagnetic compatibility Guidelines, Testing and measurement techniques.

5. Cleveland, C. J. (2005). Encyclopedia of Energy, Ph-S, vol. 5. ElsevierAcademic Press, Boston University, Boston, Massachusetts, United States.

6. Damousis, I. G., Satsios, K. J., Labridis, D. P. \& Dokopoulos, P. S. (2001). A fuzzy logic system for calculation of the interference of overhead transmission lines on buried pipelines, Electric Power Systems Research, 57(2), 105-113.

7. Damousis, I. G., Satsios, K. J., Labridis, D. P. \& Dokopoulos, P. S. (2002). Combined fuzzy logic and genetic algorithm techniques 
- application to an electromagnetic field problem, Fuzzy Sets and Systems, 129(3), 371-386.

8. Dzitac, S. (2009). Fiabilitatea şi disponibilitatea sistemelor de distribuţie a energiei electrice. Modelare şi simulare. Editura Universităţii din Oradea, ISBN978973-759-754-0.

9. European Committee for Electrotehnical Standardisation (CENELEC) (1993). SC111A: Human exposure to Electromagnetic Fields.

10. Felea, I., Coroiu, N., Demeni, L., Secui, D. C., Bendea, G. V. \& Dubau, C. (2008). Consideration on the Risk Concept for the Operating Personnel of Power Systems. In Proceedings of the Conference on Human System Interactions (HSI), Krakow, Poland, May 25-27 (pp. 959-964).

11. Felea, I., Lolea, M. \& Secui, C. (2017). Probabilistic approach of stabilized Electromagnetic field effects, Journal of Sustainable Energy, 8(3), 78-71.

12. Felea, I., Secui, C., Mușet, A. \& Dan, F. (2010). Risk assessment of the damage on the human body exposed to electromagnetic field of educational institutions, Journal of Sustenable Energy, 1(2), pp. 5. Available at: $<$ http://www.energy-cie.ro/archives/2010/ n1-2-11.pdf. $>$

13. Groumpos, P. (2018). Intelligence and Fuzzy Cognitive Maps: Scientific Issues, Challenges and Opportunities, Studies in Informatics and Control, 27(3), 247-264. DOI: $10.24846 / v 27 i 3 y 201801$

14. Hănţilă, I., Vasile, N., Demeter, E., Marinescu, S. \& Covrig, M. (1997). Câmpul electromagnetic staţionar în medii neliniare (Stationar electromagnetic field in nonneliniar medium). Editura ICPE, Bucureşti.

15. H. G. 1136 din 30/08/2006 privind cerinţele minime de securitate şi sănătate referitoare la expunerea lucrătorilor la riscuri generate de câmpuri electromagnetice (Decision 1136 from 30/08/2006 regarding the minimal security and health requirements referring on the workers expose to risk generated by electromagnetic fields), Monitorul Oficial, Partea I, nr. 769 din 11/09/2006.
16. International Commission on Non-Ionizing Radiation Protection (2009). ICNIRP Guidelines on Limits of Exposure to Static Magnetic Fields, Health Physics, 96(4), 504514. Available at: $<$ http://www.icnirp.de $>$.

17. International Standard, Commission Electrotechnique Internationale (1987). (CE 833).

18. Lakshmi, D. \& Sivakami, P. (2012). Computation of Magnetic Field Distribution by Using an Adaptive Neuro-Fuzzy Inference System, International Journal of Engineering Innovation and Research, 1(2), 175-181.

19. Matlab - Using manual.

20. Micu, D. D. et al. (2012). Neural Networks Applied in Electromagnetic Interferences problems, Revue Roumaine des Sciences Techniques - Serie Électrotechnique et Énergétique - RRST, 57(2), 162-171.

21. Nitu, V., Mingiuc, C. \& Nitu, P. (1981). Fiabilitatea şi securitatea centralelor nuclearo-electrice (Reliability and safety of nuclear-electric plants). Editura Știinţifică şi Enciclopedică, Bucureşti.

22. O.M.S. 1193 din 29 septembrie 2006 pentru aprobarea Normelor privind limitarea expunerii populaţiei generale la câmpuri electromagnetice de la $0 \mathrm{~Hz}$ la $300 \mathrm{GHz}$, Monitorul Oficial nr. 895 din 3 noiembrie 2006

23. Pănoiu, M., Pănoiu, C. \& Sora, I. (2009). Modeling the Electromagnetic Radiation of the Electric Arc Furnaces, Revue Roumaine des Sciences Techniques - Serie Électrotechnique et Énergétique - RRST, 54(2), 165-174.

24. Polk, C. (1991). Biological Effects of LowLevel Low-Frequency Electric and Magnetic Fields, IEEE Transaction on Education, 34(3), 243-249.

25. Radulović, J. \& Ranković, V. (2007). An ANFIS based approach to approximation of electromagnetic field around overhead power transmission lines, Facta Universitatis, Series: Mechanics, Automatic Control and Robotics, 6(Special Issue), 231-240.

26. Zadeh, L. (1988). Fuzzy logic, IEEE Computer, 21(4), 83-93. 
